\title{
A Comparison of the Peptide Fragmentation Obtained from a Reflector Matrix-Assisted Laser Desorption-Ionization Time-of-Flight and a Tandem Four Sector Mass Spectrometer
}

\author{
Jason C. Rouse, Wen Yu, and Stephen A. Martin \\ Genetics Institute, Inc., One Burtt Road, Andover, Massachusetts, USA
}

\begin{abstract}
The types, extent, and overall distribution of peptide fragmentation produced by matrixassisted laser desorption-ionization-postsource decay (MALDI-PSD) on a reflector time-offlight mass spectrometer were compared with those obtained from high and low energy collision-induced dissociation (CID) on a four-sector mass spectrometer and from liquid secondary ion mass spectrometry (LSIMS) ion source fragmentation and LSIMS metastable ion (MI) decomposition on a two-sector mass spectrometer. The model peptides studied had sequences and compositions that yielded predominantly either $N$ - or $C$-terminal fragmentation from CID. For des-Arg ${ }^{1}$ and des-Arg ${ }^{9}$ bradykinin (i.e., $H$-PPGFSPFR-OH and $H$-RPPGFSPF-OH, respectively), the types of fragment ions and the extent to which each type is formed in both MALDI-PSD and low energy CID spectra are remarkably similar. This observation suggests that both methods deposit comparable internal energies (IE) into $[\mathrm{M}+\mathrm{H}]^{+}$precursor ions. The distribution of $\mathrm{N}$-terminal, $\mathrm{C}$-terminal, immonium, and internal fragmentation from MALDI-PSD spectra of des- $\mathrm{Arg}^{1}$ and des-Arg ${ }^{9}$ bradykinin did not change dramatically with respect to the terminal arginine position, contrary to those from LSIMS MI decomposition, high and low energy CID spectra. This observation in combination with the prominent immonium, internal, and minus 17 fragment ion types in PSD indicates that the imparted IE from MALDI and the $14 \mu \mathrm{s}$ of flight time may promote steady-state decomposition kinetics. Fragmentation distributions of MALDI-PSD spectra are also similar to those in LSIMS spectra. This implies that the distribution of protonation sites in $[\mathrm{M}+\mathrm{H}]^{+}$ is comparable for both techniques. (J Am Soc Mass Spectrom 1995, 6, 822-835)
\end{abstract}

$\mathrm{T}$ he recent demonstrations of peptide sequencing [1-3] that employs a matrix-assisted laser desorption-ionization [4] reflector [5] time-offlight mass spectrometer [6] (MALDI-TOF-MS) has added another dimension to time-of-flight (TOF) mass spectrometry. In this technique, referred to as postsource decay (PSD) [7], excess energy is deposited into the intact protonated molecules $[\mathrm{M}+\mathrm{H}]^{+}$, which results in decomposition of a portion of these species after acceleration in the first field-free region (FFR) before the reflector. Without potential applied to the reflector, all fragment ions and corresponding neutrals from PSD are detected at the end of the first FFR as an increase in the peak width of the intact $[\mathrm{M}+\mathrm{H}]^{+}$ because they have the same approximate velocities as this precursor ion. However, these PSD fragment ions have kinetic energies (KE) that are different from each other and less than the precursor ion, and it is this characteristic that enables them to be separated by mass in the reflector. By lowering the potential applied

Address reprint requests to Dr. Jason Rouse, Genetics Institute, Inc., One Burtt Road, Andover, MA 01810. to the reflector, a particular mass range of lower $\mathrm{KE}$ fragment ions will fully penetrate the reflector comparable to that of intact $[\mathrm{M}+\mathrm{H}]^{+}$ions at full reflector potential. As a result, these specific PSD fragment ions will become focused onto the second detector at the end of the second FFR. The entire mass range of PSD fragment ions for a particular precursor ion can be detected by lowering the reflector potential in several intervals. This $\mathrm{KE}$ resolving feature of the reflector, first reported by Tang et al. [8] for peptide sequencing, is capable of obtaining fragment-ion spectra of singly charged protonated peptides with masses in excess of $10 \mathrm{ku}[2]$.

In our laboratory, we use MALDI-PSD-TOF-MS to sequence the peptides from enzymatic digests of recombinant and unknown proteins and to identify any site(s) that contains a posttranslational modification [3]. The desirable quality of PSD experiments is that 10-1000 fmol of unpurified material deposited on the MALDI target will yield at best the full sequence and at least a partial contiguous sequence for peptides with molecular weights up to $5 \mathrm{ku}$. In comparison, peptide sequence information obtained from high energy colli- 
sion-induced dissociation (CID) [9] in the third FFR of a four-sector tandem mass spectrometer [10] that is equipped with a liquid secondary ion mass spectrometry (LSIMS) $[11,12]$ ion source and a point detector requires at least $10-1000$ times more material than MALDI, no salts or buffers in the sample, and the peptide molecular weight to be below $2500 \mathrm{u}$. The advantages of high energy CID on a four-sector tandem mass spectrometer over MALDI-PSD-TOF-MS are that a higher degree of structural detail, higher mass resolution for precursor ion selection, and higher product ion mass accuracy and resolution are attainable provided enough sample is available.

In this article, we investigated the types, extent, and distribution of peptide fragmentation produced by MALDI-PSD on a reflector time-of-flight mass spectrometer (TOF-MS). These data were compared with fragmentation obtained from LSIMS ion source decomposition, LSIMS metastable ion (MI) decomposition [13] in the first FFR, and high and low energy CID in the third FFR of a tandem four-sector mass spectrometer. The series of commercially available model peptides examined in this study contained amino acid compositions and sequences that produced primarily either $N$ - or $C$-terminal fragment ion series when analyzed with the latter CID techniques. This mass spectral comparison enabled the fragmentation processes in MALDI-PSD to be characterized by using the established rules and trends for high and low energy CID and LSIMS ion source and MI decomposition. This information has provided the groundwork for interpretation of the sequence information in MALDI-PSD spectra for unknown recombinant peptides and a better understanding of how MALDI-PSD fragmentation mechanistically differs from the more established ion fragmentation methods. From a fundamental standpoint, this article compares ion fragmentation on a long time scale in MALDI-PSD-TOF-MS and on shorter time scales (in decreasing order) in LSIMS MI decomposition, low energy CID, LSIMS ion source decomposition, and high energy CID. The respective desorption-ionization technique or energetic collision method was operated under typical experimental conditions, which implies the normal predetermined average amount of internal energy (IE) was imparted into $[\mathrm{M}+\mathrm{H}]^{+}$.

\section{Experimental}

Chemicals. The peptides human adrenocorticotropic hormone fragment (ACTH) 18-39, substance $P$, human angiotensin I, angiotensin III, des- $\mathrm{Arg}^{1}$ bradykinin, des-Arg ${ }^{9}$ bradykinin, and porcine dynorphin A (1-6) used in this study were purchased from Bachem (Torrance, CA). The LSIMS matrices glycerol and 3-nitrobenzyl alcohol (NBA) were obtained from Fluka (Ronkonkoma, NY). The MALDI matrix $\alpha$-cyano-4-hydroxycinnamic acid was bought from Aldrich Chemi- cal Co. (Milwaukee, WI). All commercial materials were used without further purification.

MALDI-PSD-TOF-MS. MALDI-PSD mass spectra were acquired on a Bruker Reflex ${ }^{\mathrm{TM}}$ TOF-MS (Bruker, Billerica, MA) that was equipped with a UV (337-nm) nitrogen laser for MALDI, a single-stage acceleration ion source, and a two-stage gridless reflector. Ions are detected with dual-channel plate electron multipliers located at the ends of the first and second FFR regions. The first FFR is defined from the ion source ground grid element to the reflector entrance; the second FFR is defined from the reflector to the second detector. The ion source accelerating voltage was $28.5 \mathrm{kV}$ in all TOF experiments. For reflector mass spectra, the final lens element of the reflector was held at $30 \mathrm{kV}$. Reflector mode mass spectra were externally calibrated with the protonated molecules of angiotensin I (average MW 1296.5) and ACTH (18-39) (average MW 2465.7). These two peptides were analyzed as a mixture from $\alpha$-cyano-4-hydroxycinnamic acid matrix. Mass accuracy in the reflector mode is typically better than $0.05 \%$ in the region of the standard peptide $[\mathrm{M}+\mathrm{H}]^{+}$ masses. The base pressure in the first FFR is better than $5 \times 10^{-7}$ torr.

Complete mass spectral coverage of all peptide fragmentation required the reflector potential to be lowered in 13 intervals (see Table 1 for potentials) from $30 \mathrm{kV}$. The PSD mass spectra in this article are comprised of 14 mass spectral segments that were pasted together off-line in a two-step process with commercial graphics software on a personal computer. First, beginning with the $30-\mathrm{kV}$ segment, the signal-tobackground of each successive segment was closely matched to that of the previous segment. Second, starting with the $0.95-\mathrm{kV}$ segment, each subsequent spectral segment was normalized by using the intensities of assigned overlapping peaks in side-by-side segments as guides. This method provided a more accurate representation of the peak intensities in our experience in comparison to the on-line spectral pasting algorithm provided by Bruker. Prior to spectral pasting, mass calibration of each spectral segment was performed automatically by an algorithm developed in our lab (and incorporated into the data system by Bruker) that utilizes ACTH (18-39) as the calibrant. PSD calibration is based on a relationship between the measured (uncorrected) masses of assigned peaks in newly acquired ACTH (18-39) spectral segments and their expected average masses as demonstrated in Table 1 ( $\mathrm{Yu}, \mathrm{W}$., manuscript in preparation). The typical mass accuracies shown in Table 1 for ACTH (18-39) are generally better than $0.1 \%$ in the $\mathrm{m} / \mathrm{z}$ range between 75 and $105 \%$ of the measured precursor mass. In the acquisition of each PSD spectral segment, the signal from 25 laser shots was accumulated and the laser fluence initially was adjusted slightly above threshold and was increased only when the fragment ion abundances noticeably decreased. 
Table 1. Mass accuracy table for the ACTH (18-39) MALDI-PSD calibration spectrum (Figure 4)

\begin{tabular}{|c|c|c|c|c|c|c|}
\hline $\begin{array}{c}\text { Reflector } \\
\text { potential (kV) }\end{array}$ & $\begin{array}{l}\text { Measured } \\
\text { mass (u) }\end{array}$ & $\begin{array}{c}\text { Expected } \\
\text { ave mass }(u)\end{array}$ & $\begin{array}{l}\text { Calibrated } \\
\text { mass }(u)\end{array}$ & $\begin{array}{l}\text { Absolute } \\
\text { error (u) }\end{array}$ & $\begin{array}{l}\text { Relative } \\
\text { error (\%) }\end{array}$ & Assignment \\
\hline 0.95 & 2268.4 & 70.11 & 70.48 & 0.37 & 0.52 & $\mathbf{P}$ \\
\hline \multirow[t]{2}{*}{1.27} & 2093.3 & 87.10 & 87.15 & 0.05 & 0.05 & $R-42 / N$ \\
\hline & 2024.7 & 84.11 & 84.20 & 0.09 & 0.11 & $E-18$ \\
\hline \multirow[t]{2}{*}{1.69} & 2318.4 & 129.19 & 129.16 & -0.03 & 0.03 & $a_{1}$ \\
\hline & 2014.8 & 112.20 & 112.18 & .0 .02 & 0.02 & $R-17$ \\
\hline \multirow[t]{2}{*}{2.25} & 2270.7 & 169.25 & 169.27 & 0.02 & 0.01 & $P V-28$ \\
\hline & 1889.5 & 140.17 & 140.08 & -0.09 & 0.06 & $b_{1}-17$ \\
\hline \multirow[t]{2}{*}{3.00} & 2381.3 & 237.28 & 237.12 & -0.16 & 0.07 & $b_{2}-17$ \\
\hline & 1981.3 & 197.30 & 197.22 & -0.08 & 0.04 & PV \\
\hline \multirow[t]{2}{*}{4.00} & 2448.7 & 325.45 & 325.41 & -0.04 & 0.01 & $a_{3}$ \\
\hline & 1915.6 & 254.31 & 254.33 & 0.02 & 0.01 & $b_{2}$ \\
\hline \multirow[t]{2}{*}{5.34} & 2384.7 & 424.60 & 424.55 & -0.05 & 0.01 & PVKV \\
\hline & 1985.4 & 353.45 & 353.43 & -0.02 & 0.01 & $b_{3}$ \\
\hline \multirow[t]{2}{*}{7.12} & 2322.4 & 552.75 & 552.67 & -0.08 & 0.01 & $a_{5}$ \\
\hline & 1957.1 & 464.59 & 464.94 & 0.35 & 0.08 & $b_{4}-17$ \\
\hline \multirow[t]{2}{*}{9.49} & 2344.6 & 743.93 & 743.89 & -0.04 & 0.00 & $b_{6}$ \\
\hline & 2200.8 & 698.93 & 699.21 & 0.28 & 0.04 & $a_{6}-17$ \\
\hline \multirow[t]{2}{*}{12.66} & 2499.8 & 1055.28 & 1055.08 & -0.20 & 0.02 & $a_{10}$ \\
\hline & 2024.4 & 858.05 & 857.36 & -0.69 & 0.08 & $c_{7}$ \\
\hline \multirow[t]{2}{*}{16.88} & 2349.8 & 1327.48 & 1327.06 & -0.42 & 0.03 & $b_{12}$ \\
\hline & 2143.0 & 1212.39 & 1212.17 & -0.22 & 0.02 & $b_{11}$ \\
\hline \multirow[t]{2}{*}{22.50} & 2314.4 & 1743.87 & 1743.72 & -0.15 & 0.01 & $b_{16}$ \\
\hline & 2105.7 & 1586.76 & 1588.23 & 1.47 & 0.09 & $a_{15}$ \\
\hline \multirow[t]{2}{*}{26.25} & 2447.2 & 2144.40 & 2145.39 & 0.99 & 0.05 & $a_{20}$ \\
\hline & 1934.1 & 1698.87 & 1697.92 & -0.95 & 0.06 & $a_{16}-17$ \\
\hline 30.00 & 2465.8 & 2466.74 & 2467.86 & 1.12 & 0.05 & {$\left[\mathbf{M}+\mathbf{H}^{+}\right.$} \\
\hline
\end{tabular}

For PSD sample preparation, a $10-\mathrm{pmol} / \mu \mathrm{L}$ aqueous solution of each commercially available peptide was diluted 1:10 with a saturated $\alpha$-cyano-4-hydroxycinnamic acid matrix solution (6 mg in $500 \mu \mathrm{L}$ of $30 \%$ $\mathrm{CH}_{3} \mathrm{CN}$ in $\mathrm{H}_{2} \mathrm{O}$ plus $0.1 \%$ trifluoroacetic acid). One microliter of the resulting solution was deposited on a stainless steel probe and allowed to dry. Total peptide analyzed in each PSD experiment was $1 \mathrm{pmol}$.

LSIMS-tandem sector-MS. LSIMS ion source and MI decomposition, and all CID mass spectra were acquired on a JEOL $\mathrm{HX} 110 / \mathrm{HX} 110$ tandem $\mathrm{E}_{1} \mathrm{~B}_{1} \mathrm{E}_{2} \mathrm{~B}_{2}$ [i.e., electric (E) and magnetic (B) sector] double-focusing mass spectrometer (JEOL, Peabody, MA) that was equipped with a $\mathrm{Cs}^{+}$LSIMS ion source in MS-1 (i.e., $E_{1} B_{1}$ ) and the JEOL Complement data system. In all experiments, the ion source accelerating voltage was $10 \mathrm{kV}, \mathrm{MS}-1$ and MS-2 were operated with a mass resolution of 1000 ( $10 \%$ valley definition; in MS-2, the $\alpha$ and $\beta$ slits were opened to 7 and $5 \mathrm{~mm}$, respectively), and the linear scan rate was $1-6000 \mathrm{u} / \mathrm{min}$. The LSIMS ion source was operated with a filament current of $2.20 \mathrm{~A}$ and an applied potential of $20 \mathrm{kV}$ to produce $\mathrm{Cs}^{+}$ions with $10-\mathrm{keV} \mathrm{KE}$.

High and low energy CID experiments were performed in the third FFR between MS-1 and MS-2. The collision cell and lens assembly in this interface region were modified previously to improve ion transmission at low collision energies [14]. For high energy CID, the ${ }^{12} \mathrm{C}$ precursor ion beam was decelerated to $7 \mathrm{keV}$ (lab frame) and attenuated by $60 \%$ using helium. For low energy CID, the ${ }^{12} \mathrm{C}$ precursor ion beam was decelerated to either 45 or $50 \mathrm{eV}$ (lab frame) and attenuated by $25 \%$ with xenon. These low energy CID experimental conditions completely attenuated the high-energy product ions (i.e., $d_{n}, v_{n}$ and $w_{n}$ ) into the background, which verified low energy collisions were predominant. In all CID experiments, linked scans at constant B / E were performed in MS-2 to acquire the product-ion spectra. Mass calibration for MS-2 was performed using the alkali iodide salt mix procedure described previously [15].

LSIMS spectra were acquired in MS-1 by using B scans. Metastable decomposition of $[\mathrm{M}+\mathrm{H}]^{+}$ions from the LSIMS source were sampled from the first FFR of MS-1 (i.e., defined from the ion source ground lens element to the $\alpha$ slit) by using linked scans at constant $B / E$ in MS- 1 and ion detection after $B_{1}$ at the first detector. Mass calibration of MS-1 for $B$ and $B / E$ scans was achieved using CsI and an alkali iodide salt mix, respectively. The MI acquisition was started once the ion source pressure was at base operating pressure (better than $1 \times 10^{-6}$ torr).

In all sector experiments, $1-3 \mathrm{nmol}$ of peptide from solution were dissolved into glycerol (1:1 NBA/ glycerol for angiotensin I) matrix coated on a stainless 
steel target at the end of a direct insertion probe. Mass spectra from the sector instrument represent data accumulated from at least four scans.

\section{Results}

\section{Comparison of Ion Fragmentation Methods}

The time scales for $[\mathrm{M}+\mathrm{H}]^{+}$ion decomposition experiments in the MALDI-TOF and the tandem foursector instruments were calculated by using des-Arg ${ }^{1}$ (or des- $\mathrm{Arg}^{9}$ ) bradykinin (average MW 904.0) as the model peptide. The estimated range of IEs deposited into $[\mathrm{M}+\mathrm{H}]^{+}$by each technique also are included for comparison. The average IEs of $[\mathrm{M}+\mathrm{H}]^{+}$precursor ions that enter the third FFR for both high and low energy CID should be very low because any significant IE would result in prior decomposition in MS-1. For high energy CID, the $7-\mathrm{keV}$ des-Arg ${ }^{1}$ bradykinin precursor ions will reside in the $1-\mathrm{cm}$ collision cell for 0.3 $\mu \mathrm{s}$. During this short time period, the precursor ions must undergo collisional activation and fragmentation before reacceleration to ensure proper detection of the fragment ions in MS-2. In high energy CID under single collision conditions with $\mathrm{He}$, the maximum available collision KE for IE deposition into des-Arg ${ }^{1}$ bradykinin $[\mathrm{M}+\mathrm{H}]^{+}$precursor ions, calculated by using center-of-mass considerations [9], is $30.8 \mathrm{eV}$. Neumann et al. [16] demonstrated that the actual IE uptake by a precursor ion is only a fraction of the total center-of-mass energy, which increases with precursor mass until $1500 \mathrm{u}$. The estimated average IE imparted into a $\sim 200$-u precursor ion by high energy CID was reported to be $1-3 \mathrm{eV}$ with a high energy tail that extends out to $15 \mathrm{eV}$ [9]. In the low energy CID experiments, the residence time of des-Arg ${ }^{1}$ bradykinin precursor ions with $45 \mathrm{eV}$ of $\mathrm{KE}$ in the $1-\mathrm{cm}$ collision cell is $3.2 \mu \mathrm{s}$, which is 11 times longer than high energy CID. However, the maximum KE available for IE deposition into precursor ions is less, only $5.7 \mathrm{eV}$, based on center-of-mass considerations and single collision conditions with Xe. For low energy CID, Wysocki et al. [17] demonstrated that approximately 2-eV IE is imparted into ions of mass $\sim 200 \mathrm{u}$ with a very low probability of any high energy tail.

For MALDI-PSD, des-Arg ${ }^{1}$ bradykinin $[\mathrm{M}+\mathrm{H}]^{+}$ ions after acceleration have $13.7 \mu$ s to undergo "metastable" fragmentation in the $107-\mathrm{cm}$ first FFR before they reach the reflector, based on an accelerating voltage of $28.5 \mathrm{keV}$. In comparison, the same protonated molecules produced in and accelerated from the LSIMS source on a two-sector instrument have $8.1 \mu \mathrm{s}$ to undergo "metastable" decomposition in the $37.5-\mathrm{cm}$ first FFR, based on a 10-keV accelerating voltage. Although the average IEs of metastable $[\mathrm{M}+\mathrm{H}]^{+}$ions are not well known, they are predetermined by the respective MALDI or LSIMS desorption-ionization process. Mowry and Johnston [18] have shown previously that MALDI imparts $0.6-0.9 \mathrm{eV}$ of IE, at thresh- old irradiances, into alkylamine neutral molecules, and more recently, low molecular weight protonated amide molecules were found to have no more than $1.9-\mathrm{eV}$ IE [19]. For comparison, LSIMS was estimated to deposit on average 1.5-eV IE into preionized benzylpyridinium ions, and a substantial population of these ions had higher IEs up to $4 \mathrm{eV}$ [20]. In LSIMS MI decomposition of peptides, typically there are dominant peaks at high mass and weak peaks at low mass. Assuming a fraction of $[\mathrm{M}+\mathrm{H}]^{+}$are insufficiently activated during formation, this spectral distribution may suggest that MI undergo cyclization reactions, which involve secondary interactions between the protonated site and another region of the peptide, to form a large stable cyclic fragment ion and a small stable molecule [21]. This observation is consistent with theoretical studies that showed breaking bonds in the center of a polymeric chain is less likely than at the ends for large molecules with low IEs [22]. However, LSIMS MI spectra also may represent adequately activated $[\mathrm{M}+\mathrm{H}]^{+}$ that follow slower fragmentation pathways or undergo subsequent energizing collisions in the ion source during initial acceleration. In these two latter scenarios, IEs involved in LSIMS MI decomposition would be more similar to those from LSIMS or a CID method, respectively.

In conclusion, each technique imparts similar magnitudes of average IEs into low molecular weight precursor ions, but the upper range (including the high energy tails) of IEs imparted into $[\mathrm{M}+\mathrm{H}]^{+}$ions appear to increase in the following order: LSIMS MI decomposition (i.e., traditional low IE processes) < MALDI, low energy CID < LSIMS < high energy CID. In contrast, the inherent time for $\left[\mathrm{M}+\mathrm{H}^{+}\right.$ion decomposition in MALDI-PSD-TOF is 2- 4-, and 45-fold longer compared to that of LSIMS MI decomposition, low and high energy CID, respectively, in a tandem sector instrument for a 904-u peptide. To better understand PSD fragmentation processes, MALDI-PSD mass spectra will be compared to those obtained from the more traditional ion fragmentation methods to assess the average IE content for PSD in $[\mathrm{M}+\mathrm{H}]^{+}$precursor ions and the effects of the long decomposition time.

\section{Comparison of Mass Spectra}

Definitions. The fragment ion types, extents, and distribution in the mass spectra from each fragmentation method will be considered in the characterization of MALDI-PSD. For each thermodynamically accessible pathway, the types of fragment-product ions formed, the extent to which each fragment-product ion type is formed, and the overall distribution of fragmentation is determined by reaction kinetics, which is a function of $[\mathrm{M}+\mathrm{H}]^{+}$IE uptake (i.e, the decomposition rate increases with increasing IE in excess of the threshold reaction enthalpy), ion structure (i.e., charge location, secondary structure, steric effects, etc.), the number of other thermodynamically accessible competing and 
consecutive fragmentation reactions, and the time allowed for decomposition.

Peptide sequences in the text have the notation $\mathrm{H}$-PPGFSPFR-OH, where $\mathrm{H}$ - indicates the $\mathrm{N}$-terminus is $\mathrm{HNH}$ - and $-\mathrm{OH}$ indicates the $\mathrm{C}$-terminus is - $\mathrm{COOH}$. The nomenclature used to identify the peptide fragment ions in this article is based on that outlined by Biemann [23]. For each spectrum discussed in the following text, an accompanying pie chart will categorically show the distribution of $\mathrm{N}$-terminal sequence ions (i.e., $a_{n}, a_{n}+1, a_{n}-17, b_{n}, b_{n}-17, b_{n}+\mathrm{OH}+\mathrm{H}$, $c_{n}$, and $d_{n}$ ), $C$-terminal sequence ions (i.e., $x_{n}, y_{n}, y_{n}-$ $2, z_{n}, z_{n}+1, v_{n}$, and $w_{n}$ ), immonium ions [i.e., $\mathrm{V}=$ $\oplus \mathrm{NH}_{2}=\mathrm{CH}$ (valine side chain)] [24], internal ions [i.e., $\mathrm{VY}=H$-valine-NH-CH(tyrosine side chain)-C $\equiv$ $\mathrm{O} \oplus$ or $\mathrm{VY}-28=H$-valine- $\oplus \mathrm{NH}=\mathrm{CH}$ (tyrosine side chain)] [25], and side chain loss ions (i.e., $-\mathrm{V}=$ $[\mathrm{M}+\mathrm{H}$-(valine side chain $\left.)]^{+}\right)$. The pie chart slices for all spectra represent the summation of peak heights for all assigned ions that contribute to a particular category.

des-Arg ${ }^{1}$ bradykinin. The four-sector high energy CID mass spectrum of the peptide des-Arg ${ }^{1}$ bradykinin (average MW 904.0, $\mathrm{H}$-PPGFSPFR-OH) in Figure 1a displays a rich array of the commonly observed sequence product ion types. The presence of $d_{n}, w_{n}$, and $v_{n}$ ions in this spectrum indicates that high energy fragmentation pathways were accessible [26]. In high energy CID, a basic residue at or near the $N$ - or $C$-terminus of peptides will direct fragmentation and produce predominantly either $\mathrm{N}$ - or C-terminal ions, respectively [27]. The accompanying pie chart fragmentation distribution in Figure 1a shows that Cterminal sequence ions represent more than half $(66 \%)$ of the total ion abundance as would be expected from a peptide with a $C$-terminal arginine directing fragmentation. The four-sector 45-eV low energy CID mass spectrum in Figure $1 \mathrm{~b}$ contains only the sequence fragment ion types $a_{n}, b_{n}, y_{n}$, and $z_{n}$, which is in accordance with low energy CID data from hybrid [28] and triple-quadrupole instruments [29]. The broad peaks in all low energy CID spectra from the four-sector instrument represent the population of insufficiently activated precursor ions that undergo metastable fragmentation in the second FFR of MS-2 (i.e., between $E_{2}$ and $B_{2}$ ) [30]. For low energy CID (Figure $1 \mathrm{~b}$ ), $C$-terminal ions again represent more than half of the total ion abundance. A comparison of the MALDI-PSD mass spectrum in Figure $1 \mathrm{c}$ with low energy CID in Figure $1 \mathrm{~b}$ reveals both spectra contain identical $a_{n}, b_{n}, y_{n}$, and $z_{n}$ sequence fragment ion types with very similar fragmentation extents in each spectral region. However, a comparison of pie charts shows the distribution of fragmentation in MALDI-PSD differs from that of low energy CID because a lesser percentage of $C$-terminal ions and a greater percentage of immonium and internal ions are observed in MALDI-PSD. The LSIMS MI decomposition spectrum in Figure 1d contains some different fragment ion types (i.e., $c_{n}, w_{n}, v_{n}$, etc.) and a dissimilar extent of fragmentation in comparison to MALDI-PSD (Figure 1c). The pie chart for LSIMS MI decomposition shows more similarity to those in high and low energy CID rather than MALDI-PSD owing to the high percentage of $C$-terminal ions. For the LSIMS ion source decomposition spectrum in Figure $1 \mathrm{e}$, the $\mathrm{N}$ - and $\mathrm{C}$-terminal ion abundances in the accompanying pie chart resemble the fragmentation distribution for MALDI-PSD in Figure 1c, although more immonium and fewer internal ions are observed in the LSIMS spectrum. The overall extents of fragmentation in these two spectra are similar because low mass ion abundances are greater than high mass. However, the fragment ion types in the LSIMS spectrum more resemble those from high energy CID rather than MALDI-PSD.

des-Arg ${ }^{9}$ bradykinin. The sequence ion types in each spectral region of the des- $\mathrm{Arg}^{9}$ bradykinin (average MW 904.0, $H$-RPPGFSPF-OH) MALDI-PSD spectrum (Figure 2c) are again quite similar to those in the corresponding low energy CID spectrum (Figure $2 b$ ). The PSD fragment ion types in Figure $2 \mathrm{c}$ are again less similar to those in the high energy CID, LSIMS MI decomposition, and LSIMS spectra, in Figure 2a, d, and $e$, respectively. The overall extent of fragmentation in the MALDI-PSD spectrum (Figure 2c) is most similar to that in the low energy CID and LSIMS spectra in Figure $2 b$ and $2 e$, respectively. The MALDI-PSD pie chart fragmentation distribution (Figure $2 c$ ) is again dissimilar with that from low energy CID (Figure $2 b$ ) because a lesser percentage of $N$-terminal ions and a greater percentage of immonium and internal ions are observed for MALDI-PSD. The MALDI-PSD pie chart fragmentation distribution for des-Arg ${ }^{9}$ bradykinin is not as comparable to that for LSIMS (Figure 2e), as was noted above for des- $\mathrm{Arg}^{1}$ bradykinin, but it appears to be more analogous to that for MALDI-PSD of des-Arg ${ }^{1}$ bradykinin in Figure 1c. High similarity with the latter would indicate MALDI-PSD is somewhat insensitive to the terminal arginine position in these peptides.

Angiotensin I. Despite an increase in mass of $\sim 400$ $\mathrm{u}$, the MALDI-PSD pie chart fragmentation distribution for angiotensin I (average MW 1296.5, HDRVYIHPFHL-OH) in Figure 3a shows high resemblance to the MALDI-PSD pie charts of des-Arg ${ }^{1}$ and des-Arg ${ }^{9}$ bradykinin in Figures $1 \mathrm{c}$ and $2 \mathrm{c}$, respectively. In Figure $3 b$, the 50-eV low energy CID spectrum for angiotensin I contains comparable sequence ion types to the MALDI-PSD spectrum in Figure 3a. However, the distribution and extent of fragmentation in this spectrum is quite dissimilar compared to MALDI-PSD and, in general, it is very similar to the LSIMS-MI decomposition spectrum in Figure $3 c$. When the collision energy was increased to $110 \mathrm{eV}$ (lab frame), the low mass ions became the most intense peaks in the spectrum, and the distribution and extent of fragmen- 

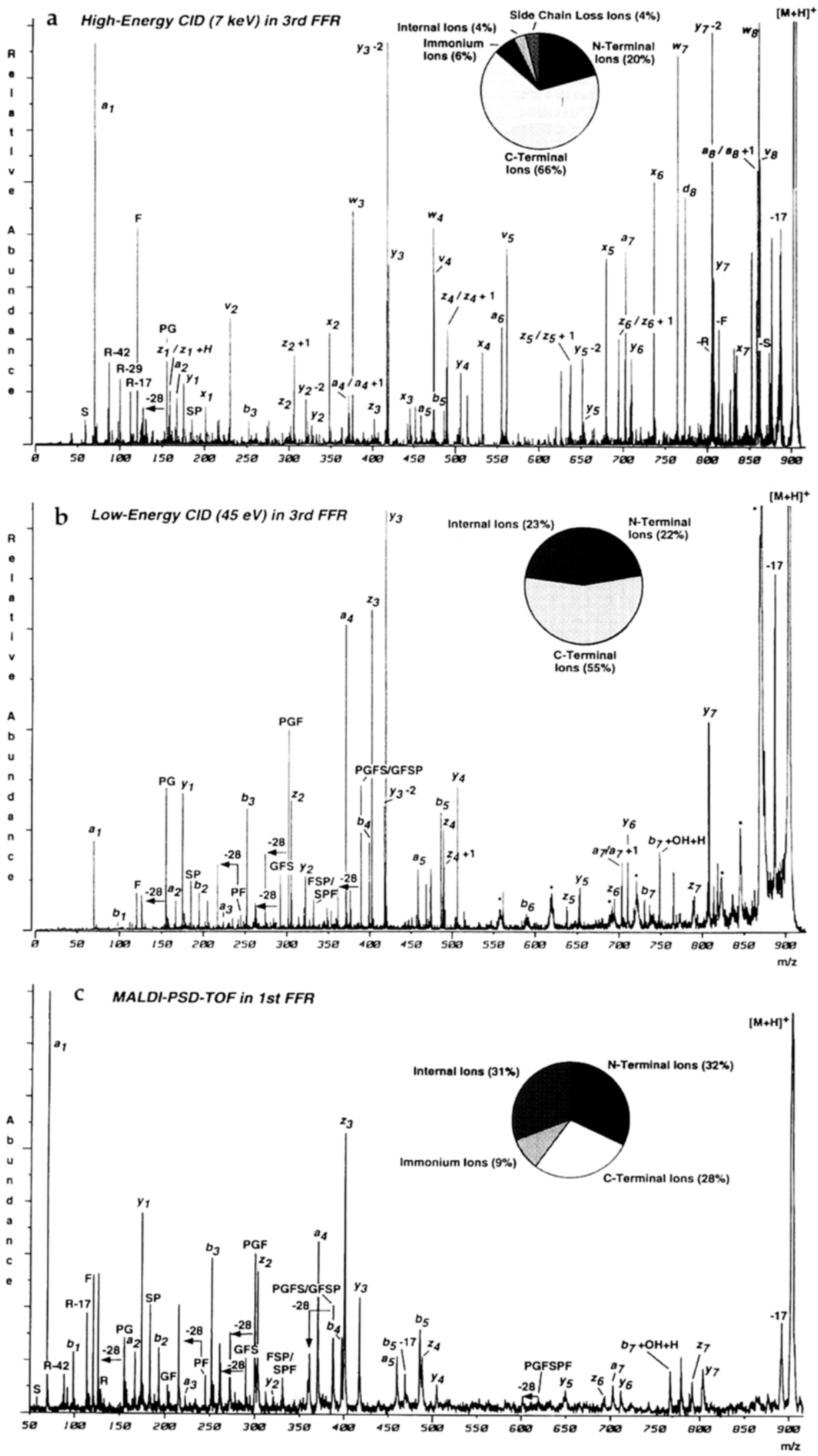

Figure 1. Des-Arg ${ }^{1}$ bradykinin (average MW 904.0), H-PPGFSPFR-OH, mass spectral comparison: (a) high-energy CID (7 keV) and (b) low energy CID (45 eV) in the third FFR of the tandem sector instrument; (c) MALDI-PSD in the first FFR of the reflector TOF-MS; (d) LSIMS MI decomposition in the first FFR of the two-sector instrument; (e) LSIMS ion source decomposition from the two-sector instrument. Glycerol and MS-2 metastable peaks are designated with an asterisk (*) in LSIMS and low energy CID spectra, respectively. See the text for a description of pie charts. 

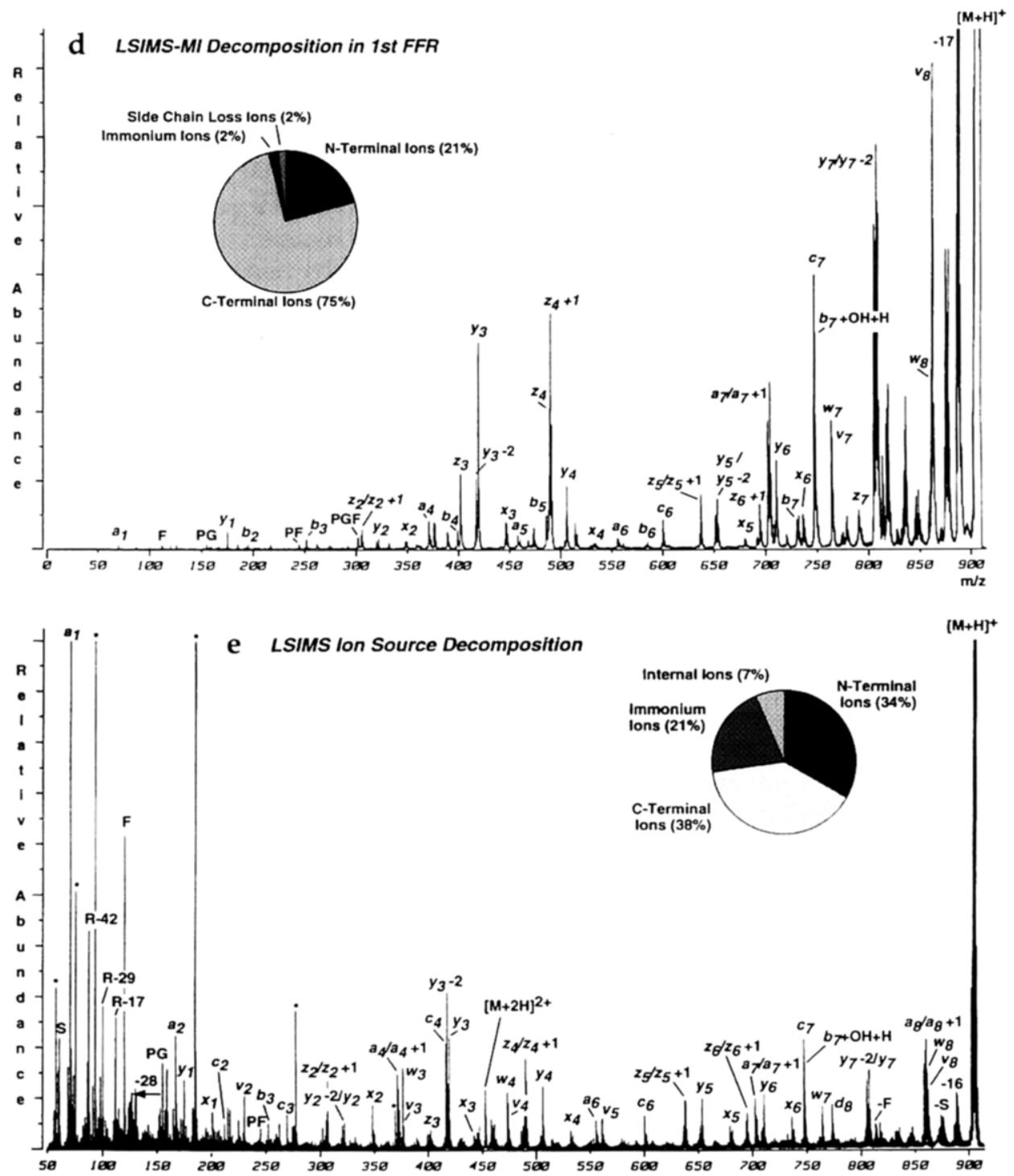

Figure 1. (continued)

tation became very similar to MALDI-PSD in Figure 3a. However, this experiment bordered on the high energy CID regime because prominent peaks that represent $d_{n}$ ions appeared in this spectrum. Thus, the lack of abundant fragmentation at low mass-to-charge ratio in the $50-\mathrm{eV}$ CID spectrum (Figure $3 \mathrm{~b}$ ) implies that a large fraction of $[\mathrm{M}+\mathrm{H}]^{+}$ions were imparted with insufficient IEs. For higher mass peptides, MALDI-PSD appears to produce more extensive peptide fragmentation in comparison to that of low energy CID on the four-sector instrument.

ACTH (18-39). The MALDI-PSD spectrum of ACTH (18-39) (average MW 2465.7, $H$-RPVKVYPNGAEDESAEAFPLEF-OH) in Figure 4 is remarkably similar in terms of fragment ion types and approximate extents of fragmentation to the previously discussed MALDIPSD spectra. However, the ACTH (18-39) fragmentation distribution, shown in the accompanying pie chart, deviates from previously discussed MALDI-PSD spectra because more than half $(59 \%)$ of the total ion abundance is related to $N$-terminal ions, whereas $C$ terminal ions comprise only $3 \%$. Immonium and internal ions comprise larger and smaller fractions, respectively, in comparison to MALDI-PSD of des-Arg ${ }^{9}$ bradykinin and comparable fractions in comparison to MALDI-PSD of angiotensin I.

\section{Discussion}

$\left[\mathrm{M}+\mathrm{H}^{+}\right.$internal energies in MALDI-PSD. Based on the des-Arg ${ }^{1}$ and des-Arg ${ }^{9}$ bradykinin mass spectral comparisons, $[\mathrm{M}+\mathrm{H}]^{+}$ions from the MALDI-PSD (Figures $1 \mathrm{c}$ and $2 \mathrm{c}$ ) experiment clearly have less IE in comparison to high energy CID (Figures $1 a$ and $2 a$ ) and LSIMS (Figures $1 \mathrm{e}$ and 2e) because no $d_{n}, w_{n,}$ and $v_{n}$ ions were observed in PSD. A comparison of LSIMS 

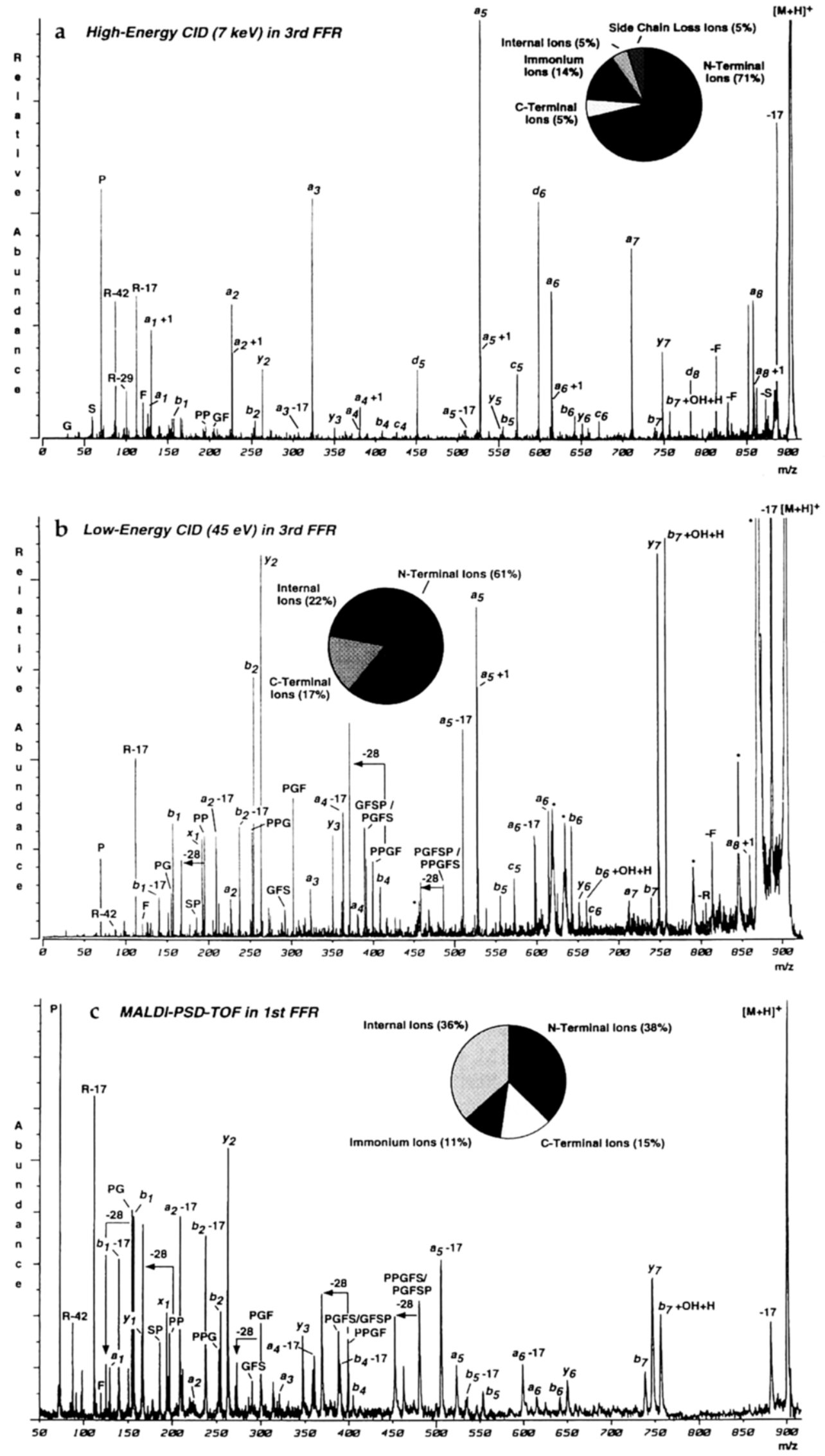

Figure 2. Des-Arg ${ }^{9}$ bradykinin (average MW 904.0), $\mathrm{H}$-RPPGFSPF-OH, mass spectral comparison: (a) 7-keV high energy CID, (b) 45-eV low energy CID, (c) MALDI-PSD-TOF, (d) LSIMS MI decomposition, and (e) LSIMS. 

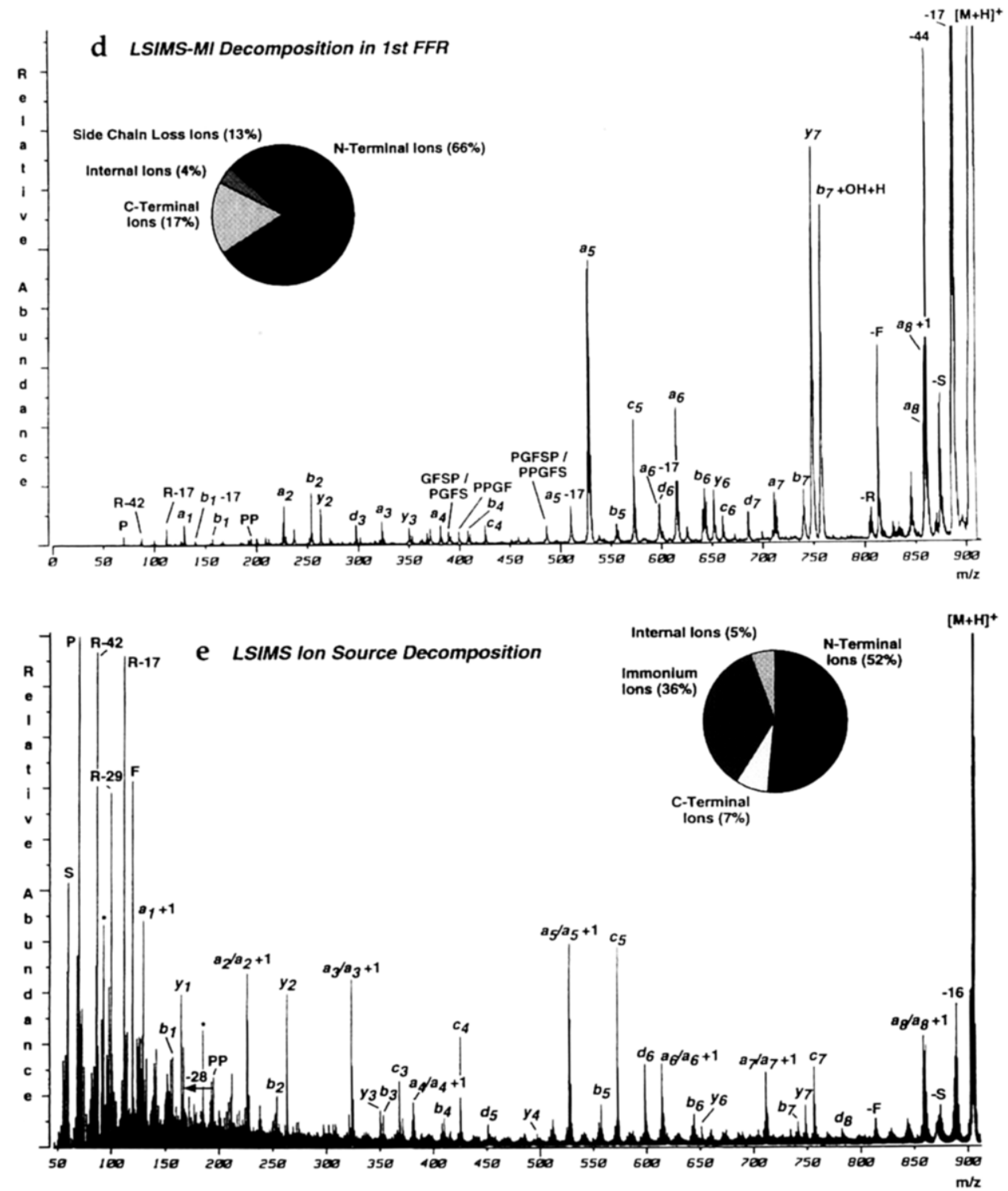

Figure 2. (continued)

MI spectra (Figures 1d and 2d) with all other spectra does not clearly indicate if the metastable $[\mathrm{M}+\mathrm{H}]^{+}$ ions have high or low IE, because the LSIMS MI spectra contain fragment ion types that are typically observed in high-energy CID (Figures 1a and 2a) and LSIMS (Figures 1e and 2e), pie chart fragmentation distributions that resemble high and low energy CID (Figures $1 \mathrm{a}, 1 \mathrm{~b}$ and $2 \mathrm{a}, 2 \mathrm{~b}$ ), and fragmentation extents that resemble those expected for traditional low energy metastable processes. It is surprising that the LSIMS MI decomposition (Figures $1 \mathrm{~d}$ and $2 \mathrm{~d}$ ) and MALDIPSD (Figures 1c and 2c) spectra have so little in common given that the inherent decomposition time scales in both techniques are extended. The fragment ion types and overall extent of fragmentation in MALDIPSD spectra (Figures $1 \mathrm{C}$ and $2 \mathrm{c}$ ) most closely resemble those from low energy CID spectra (Figures $1 \mathrm{~b}$ and $2 \mathrm{~b}$ ), and it is reasonable to assume that $[\mathrm{M}+\mathrm{H}]^{+}$ions from both experiments have similar IEs.
Spengler and co-workers [1] proposed the "insource" activation mechanism unique in MALDI to explain the abundant PSD fragmentation. Specifically, the steep acceleration field gradient inherent in MALDI ion sources will give $[\mathrm{M}+\mathrm{H}]^{+}$ions sufficient translational kinetic energy just above the target surface in the high pressure "selvedge" region [31], which consists of desorbed neutral molecules ablated from the target after a typical laser shot, such that $[\mathrm{M}+\mathrm{H}]^{+}$ ions would potentially undergo CID here. To investigate whether the "in-source" activation mechanism can impart IEs equivalent to low energy CID for PSD, a comparison of LSIMS and MALDI ion source designs, as modeled by the ion optics design and analysis computer program, SIMION $[32,33]$, was performed as described in the following text.

The SIMION ion acceleration kinematics listed in Table 2 were calculated for the typical 1000-u ion trajectory by using the MALDI and LSIMS ion source 

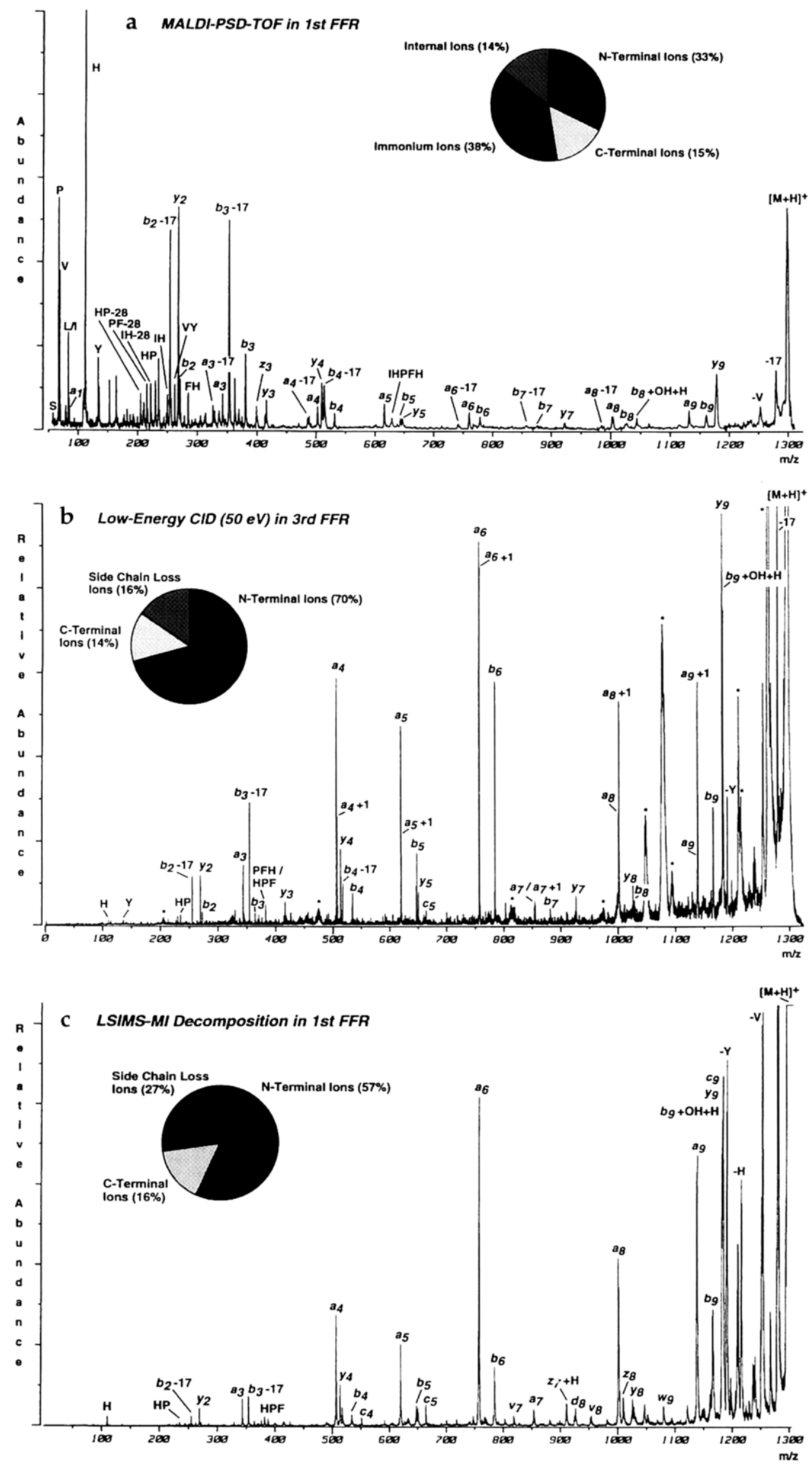

Figure 3. Human angiotensin I (average MW 1296.5), $H$-DRVYIHPFHL-OH, mass spectral comparison of (a) MALDI-PSD-TOF, (b) 50-eV low energy CID in the tandem sector instrument, and (c) LSIMS MI decomposition in the first FFR of the two-sector instrument. 


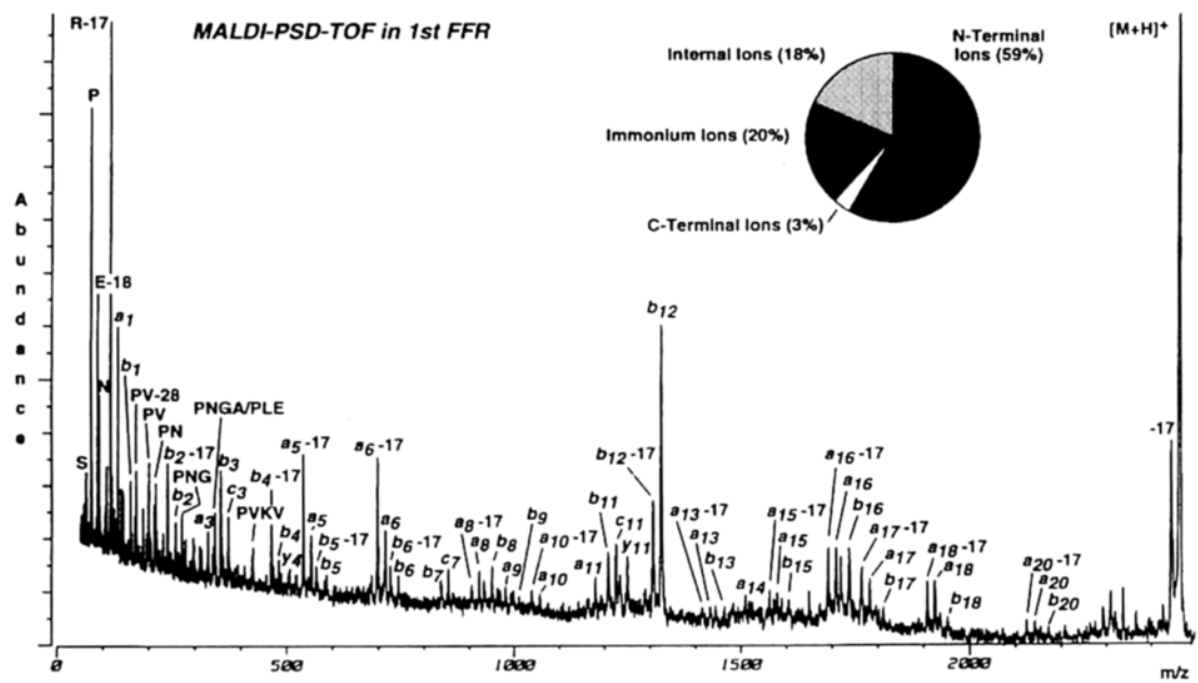

Figure 4. MALDI-PSD-TOF mass spectrum of ACTH (18-39) (average $M W$ 2465.7), $H$ RPVKVYPNGAEDESAEAFPLEF-OH, that was used for mass calibration of the MALDI-PSD spectra in Figures 1, 2, and 3 .

models shown in Figures $5 a$ and $b$, respectively. The MALDI ion source SIMION model in Figure 5 a shows ten 1000-u ion trajectories accelerated away from the sample target, which is held at $28.5 \mathrm{kV}$, toward the ground grid element, which is $1.6 \mathrm{~cm}$ away. At a distance of only $20 \mu \mathrm{m}$ above the target surface, the typical ion trajectory in this model will gain $38-\mathrm{eV} \mathrm{KE}$ in $0.015 \mu \mathrm{s}$ if we assume that no prior collisions occur.

Table 2. Comparison of ion acceleration kinematics for a typical 1000-u ion trajectory in the respective MALDI and LSIMS ion source SIMION models

\begin{tabular}{cccc}
\hline Source & Time $(\mu \mathrm{s})$ & $\begin{array}{c}\text { Distance above } \\
\text { target }(\mathrm{mm})\end{array}$ & $\begin{array}{c}\text { Kinetic } \\
\text { energy (eV) }\end{array}$ \\
\hline \hline MALDI & 0.01 & 0.009 & 17 \\
& 0.015 & 0.02 & 38 \\
& 0.02 & 0.04 & 67 \\
& 0.03 & 0.08 & 150 \\
& 0.05 & 0.22 & 418 \\
& 0.1 & 0.90 & 1.668 \\
& 0.2 & 3.58 & 6.599 \\
& 0.3 & 8.02 & 14.503 \\
& 0.4 & 14.2 & 25,268 \\
& 0.43 & 16.0 & -28.500 \\
LSIMS & 0.5 & 0.05 & 0.5 \\
& 1.0 & 0.20 & 1.5 \\
& 1.5 & 0.46 & 2.5 \\
& 2.0 & 0.87 & 5.0 \\
& 2.5 & 1.46 & 10 \\
& 3.0 & 2.23 & 23 \\
& 3.3 & 3.08 & 48 \\
3.5 & 3.88 & 178 \\
4.2 & 26.0 & $-10,000$ \\
\hline
\end{tabular}

a MALDI Ion Source

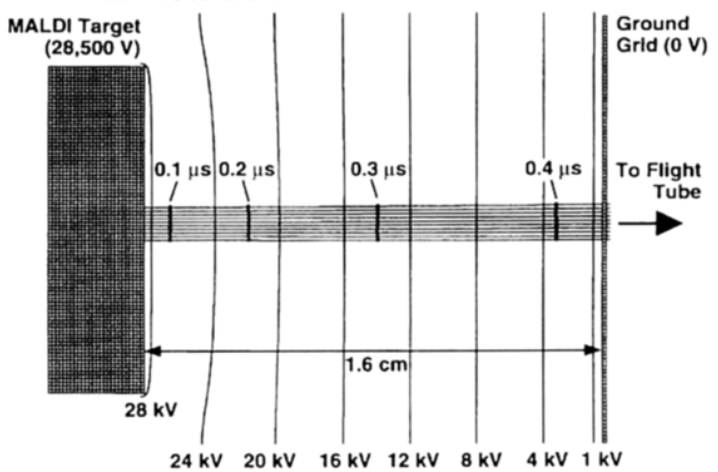

b LSIMS Ion Source

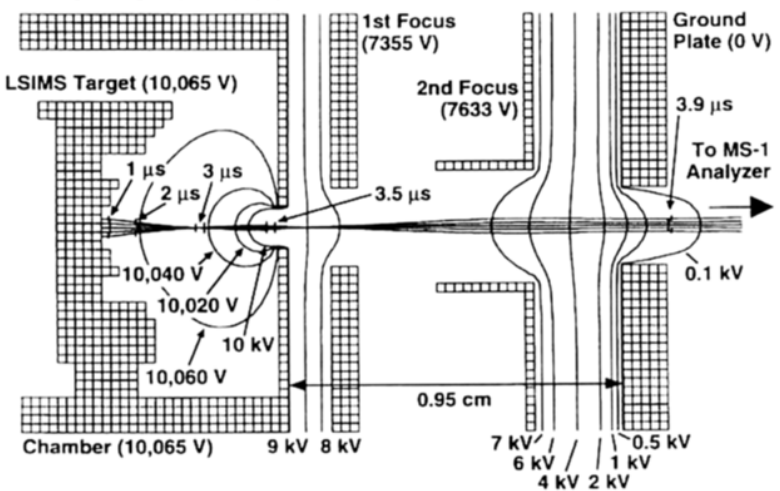

Figure 5. SIMION models of the standard (a) Bruker single-stage MALDI ion source that consists of the sample target and the ground grid element and (b) JEOL LSIMS ion source that consists of the sample target, chamber, and first focus, second focus, and ground lens elements. The potentials used in the calculations were measured from a typical experiment. Equipotential lines and time markers were calculated by SIMION. Table 2 lists the distance and $\mathrm{KE}$ values for a typical ion trajectory at the various time markers in each model above. In the respective model, the laser or kibelectronvolt $\mathrm{Cs}_{5}{ }^{+}$ion beam would originate from a point above the figure. 
In contrast, the same typical 1000-u ion in the LSIMS ion source SIMION model (Figure $5 \mathrm{~b}$ ) gains similar KEs at a distance of $\sim 3 \mathrm{~mm}$ above the target. The dramatic difference in ion source residence times is attributed to the "open" MALDI ion source design versus the narrow slit design incorporated into the LSIMS ion source, which shields the sample target from the full accelerating potential. The SIMION time and $\mathrm{KE}$ data in Table 2 indicate that the typical ion accelerated in the MALDI source will gain more KE closer to the target in less time than those in the LSIMS ion source. These attributes demonstrate that the "insource" activation mechanism is a feasible process during initial ion acceleration in MALDI.

By using simple calculations, the characteristics of the high pressure region above the MALDI target and its impact on PSD are explored. In MALDI, the molar matrix to analyte ratio for most analytes is generally greater than 1000:1. At both threshold and elevated laser fluences, the ratio of desorbed neutral molecules to ions is generally 1000:1 or greater; one report indicated 10,000:1 [34]. Thus, these estimated ratios predict that matrix molecules are the most probable species in the high pressure region above the target. Assuming there is a high pressure gradient of desorbed matrix molecules that extends out to $20 \mu \mathrm{m}$ above the target and if the $[\mathrm{M}+\mathrm{H}]^{+}$of des-Arg ${ }^{1}$ bradykinin with an initial $38 \mathrm{eV}$ of $\mathrm{KE}$ collides with an $\alpha$-cyano-4-hydroxycinnamic acid molecule (MW 189) here, the calculated center-of-mass collision energy (i.e., assuming single collision conditions) would be $6.6 \mathrm{eV}$, which is very similar to that of low energy CID performed on the tandem sector instrument in this article. By using simple calculations previously described by Pachuta and Cooks [35] for LSIMS, the pressure $20 \mu \mathrm{m}$ above the probe will be in the millitorr region if 10,000 matrix molecules are ablated with $1 \mathrm{eV}$ of $\mathrm{KE}$ into a $8000-\mu \mathrm{m}^{3}$ [i.e., $(20-\mu \mathrm{m})^{3}$ ] volume. The high extent of fragmentation in MALDI-PSD supports the notion that there is a specific region above the target where CID occurs, but whether single or multiple collisions are predominant remains unknown.

Additional IE deposition into $[\mathrm{M}+\mathrm{H}]^{+}$ions from the desorption and ionization steps in MALDI also is expected as in LSIMS [36]. The lack of a high energy tail in MALDI in contrast to LSIMS suggests that the desorption and/or ion formation mechanisms in LSIMS are fundamentally different from MALDI. However, high laser fluences, which are required for PSD fragmentation in MALDI, induced some prompt fragmentation (i.e., fragmentation before initial acceleration) in peptides because small molecule losses and an increase in the precursor ion peak width were observed. In conclusion, whether excitation of $[\mathrm{M}+\mathrm{H}]^{+}$ions in MALDI arises from thermal energy transfer in the matrix, gas-phase protonation, and /or "in-source" activation above the target, the total amount of IE deposited appears to be equivalent to that imparted by low energy CID.
Protonated structures of PSD precursor ions. The overall distribution of fragmentation in des-Arg ${ }^{1}$ and des-Arg ${ }^{9}$ bradykinin MALDI-PSD spectra (Figures $1 \mathrm{c}$ and 2c) is more comparable to that of LSIMS ion source fragmentation spectra (Figures 1e and 2e) than those of LSIMS MI decomposition (Figures 1d and 2d) or high (Figures $1 a$ and $2 a$ ) and low energy CID (Figures $1 b$ and $2 b$ ). In fact, the pie charts that accompany MALDI-PSD (Figures $1 \mathrm{c}$ and 2c) and LSIMS ion source decomposition (Figures 1e and 2e) show nearly equivalent amounts of $\mathrm{C}$ - and $\mathrm{N}$-terminal fragmentation with the exception of Figure 2e (see succeeding text for explanation). This observation would suggest similar protonated peptide structures exist just prior to fragmentation in both MALDI and LSIMS if we assume that PSD is actually "delayed" ion source fragmentation rather than "metastable" decomposition. In LSIMS, ion source fragmentation of $[\mathrm{M}+\mathrm{H}]^{+}$ions is observed prior to acceleration because there is ample time for decomposition, given that it takes $1 \mu \mathrm{s}$ for $[\mathrm{M}+\mathrm{H}]^{+}$to gain only 1.5-eV KE and $4.2 \mu \mathrm{s}$ to gain full KE (see Table 2). In MALDI, the initial and full acceleration times are drastically shorter, given that it takes $30 \mathrm{~ns}$ for [M + $\mathrm{H}]^{+}$to gain $150 \mathrm{eV}$ of $\mathrm{KE}$ and $\sim 400 \mathrm{~ns}$ to gain full $\mathrm{KE}$ (see Table 2). Assuming the IE upper limit imparted into $[\mathrm{M}+\mathrm{H}]^{+}$ions by MALDI is comparable to the average IE imparted by LSIMS and the majority of $[\mathrm{M}+\mathrm{H}]^{+}$ions produced by MALDI at high and low laser fluences do not fragment within $30 \mathrm{~ns}$, PSD of $[\mathrm{M}+\mathrm{H}]^{+}$ions in MALDI is probably no more than "delayed" ion source fragmentation [37]. Thus, for LSIMS ion source and MALDI-PSD decomposition, the $[\mathrm{M}+\mathrm{H}]^{+}$ions with sufficient IEs and protonation sites near the site of bond cleavage(s) should fragment soon after formation. The remaining unfragmented $[\mathrm{M}+\mathrm{H}]^{+}$ions would be expected to have low IEs and/or protonation sites remote from the site of fragmentation, and these ions would be candidates for fragmentation in LSIMS MI decomposition if rearrangement reactions occur in the generous first FFR time frame, and in low and high energy CID after reactivation and/or redistribution of the protonation site.

Steady-state fragmentation in MALDI-PSD. A majority of the prominent peaks in the MALDI-PSD spectra for both des-Arg ${ }^{1}$ and des-Arg ${ }^{9}$ bradykinin (Figures $1 \mathrm{c}$ and $2 \mathrm{c}$ ) represent the sequence ions minus 17 (i.e., $a_{n}-17, b_{n}-17$, and $y_{n}-17$, which is isobaric to $z_{n}$; most likely due to the loss of $\mathrm{NH}_{3}$ ), internal ions, and immonium ions. All of these ion types can be considered fragmentation "endpoints" because each type potentially undergoes multiple bond cleavages through a consecutive decomposition pathway within the generous TOF time frame. In the respective high energy CID (Figures $1 a$ and 2a) and LSIMS (Figures $1 e$ and 2e) spectra, the minus 17 and internal ion types appear not to be favored. This indicates either time is not available for these subsequent fragmentation reactions or 
other simple cleavage reactions are more competitive given higher average IEs are available. In the LSIMS MI spectra (Figures $1 d$ and $2 \mathrm{~d}$ ), these "endpoint" fragment ion types also are not favored, unlike MALDIPSD, even though ample time is available, which suggests metastable ions may have too little IE available for subsequent fragmentation. As in MALDI-PSD, the respective low energy CID spectra (Figures $1 b$ and $2 b$ ) contain each of these "endpoint" fragment ion types, but they are not as extensively produced. This observation correlates well with more decomposition time being available in MALDI-PSD. Last, the pie chart fragmentation distributions from MALDI-PSD of des$\mathrm{Arg}^{1}$ and des-Arg ${ }^{9}$ bradykinin in Figures $1 \mathrm{c}$ and $2 \mathrm{c}$, respectively, contain similar fractions of $N$ - and $C$ terminal fragmentation which indicates MALDI-PSD is somewhat insensitive to the location of terminal basic residues in these two peptides, whereas low energy $\mathrm{CID}$ (Figures $1 \mathrm{~b}$ and $2 \mathrm{~b}$ ) is not. This again suggests time, in conjunction with the predetermined average $[\mathrm{M}+\mathrm{H}]^{+}$IE content and the distribution of protonation sites, are the important factors in MALDI-PSD for production fragmentation with similar distributions. Thus, for MALDI-PSD of des-Arg ${ }^{1}$ and des-Arg ${ }^{9}$ bradykinin, the presence of unique "endpoint" fragment ion types and the similar fragmentation distributions, independent of the terminal arginine position, would suggest that steady-state fragmentation is achieved.

The pie chart fragmentation distributions for the higher mass peptides angiotensin I (Figure 3a) and ACTH (18-39) (Figure 4) differ in comparison to lower mass des-Arg ${ }^{1}$ and des-Arg ${ }^{9}$ bradykinin (Figures 1 and 2c) peptides. However, the "endpoint" fragment ion types remain dominant in PSD spectra at all peptide masses. For peptides with an $N$-terminal basic residue, the general trend observed in MALDI-PSD for the des-Arg ${ }^{9}$ bradykinin, angiotensin $\mathrm{I}$, and $\mathrm{ACTH}$ (18-39) fragmentation distributions is that the fraction of $\mathrm{N}$-terminal ions increases and the fraction of $\mathrm{C}$ terminal cons decreases as the mass increases. In support, the MALDI-PSD pie chart fragmentation distributions of angiotensin III (average MW 931.1, $\mathrm{H}$ RVYIHPF-OH) and substance P (average MW 1347.7, $\mathrm{H}$-RPKPQQFFGLM-NH $\mathrm{H}_{2}$ ) were $42 \%: 17 \%: 29 \%: 12 \%$ (i.e., $\mathrm{N}$-terminal, $\mathrm{C}$-terminal, immonium, and internal ion abundances, respectively) and 57\%:2\%:28\%:13\%, respectively. This trend may suggest that the same degree of steady-state fragmentation observed for lower mass peptides is less obtainable with higher mass peptides and/or perhaps more C-terminal ions fragment further into internal and immonium ions for higher mass peptides. In contrast, the MALDI-PSD fragmentation distribution for a 2103-u peptide (from a recombinant glycoprotein) with a C-terminal basic residue was 20\%:32\%:30\%:18\% (i.e., $N$-terminal, $C$ terminal, immonium, and internal ion abundances, respectively) (Huberty, M. C., Genetics Institute, personal communication). This distribution is comparable to those for MALDI-PSD of des-Arg ${ }^{1}$ bradykinin (Figure 1c) and LSIMS ion source decomposition (Figure 1e) spectra, and also dynorphin A 1-6 (average MW 711.8, $\mathrm{H}$-YGGFLR-OH), which was 37\%:30\%:19\%:14\%. The general trend observed for these peptides with a $\mathrm{C}$-terminal basic residue is that the fractions of $\mathrm{N}$ - and $C$-terminal ions remains somewhat constant at both low and high mass. The exact ratios of internal and immonium ion abundances for peptides of high and low mass in MALDI-PSD is less clear, but it is thought to depend on the peptide sequence and composition under investigation. In the interpretation of unknown PSD spectra, the always abundant immonium and internal ions help confirm the derived composition and sequence. It is interesting to note that the pie chart fragmentation distributions for higher mass peptides analyzed by MALDI-PSD [e.g., ACTH (18-39)] highly resemble those for lower mass peptides analyzed by LSIMS ion source decomposition (e.g., des-Arg ${ }^{9}$ bradykinin). This observation suggests that for higher mass peptides it is more beneficial to give $[\mathrm{M}+\mathrm{H}]^{+}$ ions larger amounts of time to fragment as in MALDIPSD, rather than to deposit more IE.

\section{Conclusions}

Matching fragment ion types with similar extents of fragmentation were encountered in both MALDI-PSD and low energy CID spectra for peptides. This suggests that both techniques impart $[\mathrm{M}+\mathrm{H}]^{+}$with similar average IEs. The overall distribution of $N$-terminal, C-terminal, immonium, and internal fragment ion types in MALDI-PSD was most comparable to that from LSIMS ion source fragmentation, which suggests the distribution of protonated sites in $[\mathrm{M}+\mathrm{H}]^{+}$ions from MALDI and LSIMS are comparable just before fragmentation. The predominant immonium, internal and minus 17 fragment ion types and the near equivalent fragmentation distributions for MALDI-PSD of des$\operatorname{Arg}^{1}$ and des- $\operatorname{Arg}^{9}$ bradykinin indicates that steadystate fragmentation can be achieved at low mass.

Complete peptide sequence information for peptides higher than 2500-u becomes increasingly difficult to obtain in MALDI-PSD. As in CID, the success rate for MALDI-PSD ultimately depends on the peptide composition and sequence under investigation. To potentially increase the yield of weak or missing sequence ions in MALDI-PSD, the desorption, ion formation, and "in-source" activation mechanisms need further understanding at low and high laser fluence. The fragmentation from MALDI-PSD may potentially be improved by adjusting the number of matrix molecules ablated into the gas phase through sample preparation and/or by using an adjustable multistage acceleration field. Perhaps performance of high energy CID on $[\mathrm{M}+\mathrm{H}]^{+}$ions as they exit from the MALDI ion source would reduce the need for high laser fluence in PSD acquisition, enhance the present low energy fragmen- 
tation, and/or provide additional complementary high energy fragmentation.

\section{Acknowledgments}

The authors thank Dr. Hubert Scoble, Dr. James Vath, and Michael Huberty at Genetics Institute for their support and critical review of this manuscript.

\section{References}

1. Kaufmann, R.; Spengler, B.; Lützenkirchen, F. Rapid Commun. Mass Spectrom. 1993, 7, 902.

2. Yu, W.; Vath, J. E.; Huberty, M. C.; Martin, S. A. Anal. Chem. 1993, 65, 3015

3. Huberty, M. C.; Vath, J. E.; Yu, W.; Martin, S. A. Annl. Chem. 1993, 65, 2791.

4. Hillenkamp, F.; Karas, M.; Beavis, R. C.; Chait, B. T. Anal. Chem. 1991, 63, 1193A.

5. Mamyrin, B. A.; Karataev, V. I.; Shmikk, D. V.; Zagulin, V. A. Sov. Pliys. JETP 1973, 37, 45.

6. Cotter, R. J. In Time-of-Flight Mass Spectrometry; Cotter, R. J., Ed.; ACS Symposium Series 549; American Chemical Society: Washington, DC, 1994; Chap. 2.

7. Spengler, B.; Kirsch, D.; Kaufmann, R. J. Phys. Chem. 1992, 96, 9678.

8. Tang, X.; Ens, W.; Standing, K. G.; Westmore, J. B. Anal. Chem. 1988, 60, 1791.

9. Hayes, R. N.; Gross, M. L. In Mass Spectrometry; McCloskey, J. A., Ed.; Methods in Enzymology, Vol. 193; Academic: San Diego, CA, 1990; Chap. 10.

10. Gross, M. L. In Mass Spectrometry; McCloskey, J. A., Ed.; Methods in Enzymology; Vol. 193; Academic: San Diego, CA, 1990; Chap. 6.

11. Aberth, W. H.; Burlingame, A. L. Anal. Chem. 1988, 60, 1426.

12. DePauw, E.; Agnello, A.; Derwa, F. Mass Spectrom. Rev. 1991, 10, 283.

13. Cooks, R. G.; Beynon, J. H.; Caprioli, R. M.; Lester, G. R. Metastable Ions; Elsevier: New York, 1973.

14. Yu, W.; Martin, S. A. J. Am. Soc. Mass Spectrom. 1994, 5, 460.

15. Sato, K.; Asada, T.; Ishihara, M.; Kunihiro, F.; Kammei, Y.; Kubota, E.; Costello, C. E.; Martin, S. A.; Scoble, H. A.; Biemann, K. Anal. Chem. 1987, 59, 1652.

16. Neumann, G. M.; Sheil, M. M.; Derrick, P. J. Z. Naturforsch. 1984, 39A, 584.
17. Wysocki, V. H.; Kenttämaa, H. I.; Cooks, R. G. Int. J. Mass Spectrom. Ion Processes 1987, 75, 181.

18. Mowry, C. D.; Johnston, M. V. I. Phys. Chem. 1994, 98, 1904.

19. Bentzley, C. M.; Johnston, M. V. Proceedings of the 42nd ASMS Conference on Mass Spectrometry and Allied Topics; Chicago, IL, June 1994; $\mathrm{p} 948$.

20. Derwa, F.; DePauw, E.; Natalis, P. Org. Mass Spectrom. 1991, $26,117$.

21. Rouse, J. C. Ph.D. Dissertation, Michigan State University, 1993.

22. Bunker, D. L.; Wang, F.-M. I. Am. Chem. Soc. 1977, 99, 7457.

23. Biemann, K. In Mass Spectrometry; McCloskey, J. A., Ed.; Methods in Enzymology, Vol. 193; Academic: San Diego, CA, 1990; Chaps. 18, 25 and Appendix 5.

24. Falick, A. M.; Hines, W. M.; Medzihradszky, K. F.; Baldwin, M. A.; Gibson, B. W. I. Am. Soc. Mass Spectrom. 1993, 4, 882.

25. Ballard, K. D.; Gaskell, S. J. Int. I. Mass Spectrom. Ion Processes 1991, 111, 173.

26. Johnson, R. S.; Martin, S. A.; Biemann, K. Int. J. Mass Spectrom. Ion Processes 1988, 86, 137.

27. Bunk, D. M.; Macfarlane, R. D. Int. I. Mass Spectrom. Ion Processes 1991, 111, 55.

28. Bean, M. F.; Carr, S. A.; Thorne, G. C.; Reilly, M. H.; Gaskell, S. J. Anal. Chem. 1991, 63, 1473.

29. Hunt, D. F.; Yates, J. R.; Shabanowitz, J.; Winston, S.; Hauer, C. R. Proc. Natl. Acad. Sci. USA 1986, 83, 6233.

30. Falick, A. M.; Medzihradszky, K. F.; Walls, F. C. Rapid Commun. Mass Spectrom. 1990, 4, 319.

31. Rouse, J. C.; Allison, J. J. Am. Soc. Mass Spectrom. 1993, 4, 259.

32. Dahl, D. A.; Delmore J. E. SIMION PC/PS2 Version 4.0, EGG-CS-7233 Rev. 2, April 1988.

33. Dahl, D. A.; Delmore, J. E.; Appelhans, A. D. Rev. Sci Instrum. 1990, 61, 607.

34. Mowry, C. D.; Johnston, M. V. Rapid Commun. Mass Spectrom. $1993,7,569$.

35. Pachuta, S. J.; Cooks, R. G. In Desorption Mass Spectrometry: Are SIMS and FAB the Same?; Lyons, P. A., Ed.; ACS Symposium Series 291; American Chemical Society: Washington, DC, 1985; Chap. 1.

36. Ehring, H.; Karas, M.; Hillenkamp, F. Org. Mass Spectrom. 1992, 27, 472.

37. Olthoff, J. K.; Honovich, J. P.; Cotter, R. J. Anal. Chem. 1987, $59,999$. 